\title{
PRÁTICAS DE COMPARTILHAMENTO DE CONHECIMENTO EM COMUNIDADES DE PRÁTICA MULTIALOCADAS: UMA REVISÃO INTEGRATIVA
}

\author{
(iD) Adriana Karam-Kolesk ${ }^{1}$, Cristiano José Castro de Almeida Cunha ${ }^{2}$, ${ }_{\text {Solange Maria da Silva }}{ }^{3}$, Eduardo \\ Moreira da Costa \\ ${ }^{1}$ Universidade Federal de Santa Catarina (UFSC), Florianópolis, Santa Catarina, Brasil e Centro Universitário Opet \\ (UniOpet), Curitiba, Paraná, Brasil.adriana@opet.com.br \\ ${ }^{2}$ Universidade Federal de Santa Catarina (UFSC), Florianópolis, Santa Catarina, Brasil. 01cunha@ gmail.com \\ ${ }^{3}$ Universidade Federal de Santa Catarina (UFSC), Florianópolis, Santa Catarina, Brasil. solange.silva@ufsc.br \\ 4Universidade Federal de Santa Catarina (UFSC), Florianópolis, Santa Catarina, Brasil. educostainovacao@gmail.com
}

\section{Resumo}

Objetivo do estudo: Compreender as práticas de compartilhamento de conhecimento utilizadas em comunidades de prática que têm pontos de contato espalhados geograficamente. Tais comunidades, denominadas de "Comunidades de Prática (CoPs) Multialocadas", precisam se valer de práticas diferenciadas para compartilhar seu conhecimento.

Metodologia/abordagem: Realizou-se uma revisão integrativa, com consulta às bases de dados Scopus, Web of Science e SciELO, com análise temática dos artigos revisados.

Originalidade/Relevância: As CoPs intraorganizacionais e suas iniciativas de compartilhamento de conhecimento têm sido amplamente discutidas na literatura. No entanto, CoPs multialocadas e suas práticas de compartilhamento de conhecimento ainda são pouco estudadas.

Principais resultados: Foram identificadas e discutidas quatro dimensões de práticas de compartilhamento de conhecimento: 1) "Lugar integrador", 2) "De tomadores a compartilhadores de conhecimento", 3) "Promoção de conexões" e 4) "Implantação e sustentação".

Contribuições: $O$ artigo tem contribuições em duas linhas principais: 1) as dimensões identificadas podem oferecer subsídios para a análise de processos de compartilhamento de conhecimento em comunidades de prática desta natureza e 2) as práticas apresentadas podem colaborar com a qualificação e enriquecimento de projetos de compartilhamento de conhecimento em CoPs multialocadas em formação ou já existentes.

Conclusão: Não há um conjunto padrão de práticas de compartilhamento de conhecimento em CoPs multialocadas. O denominador comum é que a escolha de tais práticas deve levar em consideração os objetivos da comunidade, as características de seus membros, a natureza do conteúdo a ser compartilhado, os canais de compartilhamento de conhecimento e também os recursos disponíveis.

Palavras-chave: Gestão do conhecimento. Comunidades de prática. Comunidades de prática multialocadas. Comunidades de conhecimento. Práticas de compartilhamento de conhecimento.

\section{KNOWLEDGE SHARING PRACTICES IN MULTI-ALLOCATED} COMMUNITIES OF PRACTICE: AN INTEGRATIVE REVIEW.

\section{Abstract}

Purpose: The purpose of this paper is to understand knowledge sharing practices used by communities of practice which have their points of contact spread geographically. These communities, denominated "multi-allocated Communities of Practice" (CoPs), need to use specific practices to share their knowledge.

Methodology: Integrative review of articles accessed at the databases: Scopus, Web of Science and SciELO. The articles were analyzed by means of thematic analysis.

Originality: Intraorganizational $\mathrm{CoPs}$ and their knowledge sharing initiatives have been widely studied. However, multi-allocated CoPs and their knowledge sharing practices still lack study.

Findings: Four dimensions of knowledge sharing practices were identified and discussed: "Integrative place", "From takers to knowledge sharers", "Promoting connections" and "Implementing and sustaining".

Contributions: This article presents contributions in two main aspects: 1) the dimensions which were identified can offer subsidies for the analysis of processes of knowledge sharing in communities of practice of this nature and 2) presented practices can collaborate with the qualification and enrichment of knowledge sharing practices in new or existing multi-allocated CoPs projects.

Conclusions: There is no standard array of knowledge sharing practices in multi-allocated CoPs. The common denominator is that the choice of these practices must take in consideration the objectives of the community, it's members' characteristics, the nature of knowledge to be shared, as well as knowledge sharing channels and resources that are available.

Keywords: Knowledge management. Communities of practice. Multi allocated communities of practice. Knowledge communities. Knowledge sharing practices

PRÁCTICAS DE INTERCAMBIO DE CONOCIMIENTOS EN COMUNIDADES DE PRÁCTICA CON MÚLTIPLES ASIGNACIONES: UNA REVISIÓN INTEGRADORA

\section{Resumen}

Objetivo: Comprender las prácticas de intercambio de conocimientos utilizadas en comunidades de práctica que tienen puntos de contacto distribuidos geográficamente. Estos comunidades, llamadas "Comunidades de práctica de asignación múltiple (CoPs)", necesitan usar prácticas diferenciadas para compartir sus conocimientos.

Metodología / enfoque: Se realizó una revisión integradora, consultando las bases de datos Scopus, Web of Science y SciELO, con análisis temático de los artículos revisados.

Originalidad / relevancia: Las CoPs intraorganizacionales y sus iniciativas de intercambio de conocimientos han sido ampliamente discutidas en la literatura. Sin embargo, las CoPs asignadas de manera múltiple y sus prácticas de intercambio de conocimientos aún están poco estudiadas.

Resultados principales: Se identificaron y discutieron cuatro dimensiones de las prácticas de intercambio de conocimientos: 1) "Lugar de integración", 2) "De los prestatarios al intercambio de conocimientos", 3) "Promoción de conexiones" y 4) "Implementación y apoyo".

Contribuciones: El artículo tiene contribuciones en dos líneas principales: 1) las dimensiones identificadas pueden ofrecer subsidios para el análisis de los procesos de intercambio de conocimientos en comunidades de práctica multi-asignadas; 2) las prácticas presentadas pueden colaborar con la calificación y el enriquecimiento de proyectos de intercambio de conocimientos en CoPs multi-asignadas existentes o en creación.

Conclusión: No existe un conjunto estándar de prácticas de intercambio de conocimientos en CoPs con múltiples asignaciones. El denominador común es que la elección de tales prácticas debe tener en cuenta los objetivos de la comunidad, las características de sus miembros, la naturaleza del contenido que se compartirá, los canales para compartir el conocimiento y también los recursos disponibles.

Palabras clave: gestión del conocimiento; comunidades de práctica; comunidades de práctica con múltiples asignaciones; comunidades de conocimiento; prácticas de intercambio de conocimientos. 


\section{Introdução}

Na sociedade do conhecimento, o capital intelectual de uma organização passou a ser essencial para seu sucesso. Composto pelos conhecimentos que trazem valor para o negócio (Bontis \& Nikitopoulos, 2001), o capital intelectual pode estar registrado em patentes, propriedade intelectual, processos e documentos, mas é constituído, em sua maioria, por conhecimentos, experiência e expertise de membros da organização (Nonaka \& Takeuchi, 1995). Neste sentido, é preciso que tais conhecimentos fluam na organização para que possam cumprir seu papel de colaborar para o atingimento dos objetivos organizacionais.

Se o desafio de fazer o conhecimento fluir dentro das organizações é grande, em empreendimentos interorganizacionais ou entre indivíduos pertencentes a diferentes organizações, o desafio é ainda maior (Husted \& Michailova, 2009). No entanto, os benefícios compensam o desafio, pois a parceria entre organizações e pessoas de diferentes contextos cria um canal em que podem fluir informação, experiências, valores, práticas e procedimentos (T. H. Davenport \& Prusak, 1998). Trata-se de um mecanismo eficiente para aquisição de conhecimento, que colabora na manutenção da competitividade das organizações, ao oferecer subsídios para sua atualização e inovação (Rathi, Given, \& Forcier, 2014).

Inúmeros mecanismos para o compartilhamento de conhecimento são apontados na literatura (APO, 2009; Dalkir, 2005; NHS, 2005). Dentre eles, destaca-se o uso de comunidades de diversas naturezas. Sustentadas pelo entendimento da aprendizagem como fenômeno social, as comunidades são eficientes mecanismos de agregação social, pois acabam por formar redes de comunicação, que reforçam o senso de identificação dos indivíduos e estimulam o desenvolvimento de confiança, reciprocidade e cooperação (Dalkir, 2005). Estes atributos colaboram para que o compartilhamento de conhecimento não se limite à promoção de uma maior eficiência no uso do conhecimento existente nas organizações, mas também da criação de novos conhecimentos e promoção de inovação (Basile, 2009; Cheng, 2015; Nonaka \& Takeuchi, 1995).

As comunidades podem ser de aprendizagem e de conhecimento quando são formadas pelo interesse de uma organização ou grupo de pessoas em desenvolver aprendizagem e descobrir, usar e manipular conhecimento em uma área específica, a partir da interação entre seus participantes. Essas comunidades têm uma estrutura, seus membros são usualmente definidos pela liderança e pelo papel que desempenham na organização (Dalkir, 2005; Kezar \& Gehrke, 2015). As comunidades de aprendizagem podem ser definidas como "grupos de indivíduos comprometidos em trabalhar, de modo colaborativo, em processos contínuos de questionamento e pesquisa-ação para atingir melhores resultados" (Kezar \& Gehrke, 2015, p. 20).

As pesquisas sobre aprendizagem em comunidades no mundo dos negócios ganharam espaço com o trabalho de Etienne Wenger, pioneira no estudo de comunidades de prática (CoPs). O termo “comunidades de prática", cunhado por Wenger e Snyder em 1991, designa "grupos de pessoas 
informalmente reunidas por expertise compartilhada e paixão por um objetivo comum"(Wenger \& Snyder, 2000, p. 39). Em sua concepção inicial, as comunidades de prática eram formadas organicamente, a partir do interesse de seus participantes, eram autodirigidas e a participação em suas atividades era voluntária e realizada de acordo com regras próprias da comunidade. Podiam ter o apoio da organização, mas esse apoio não era mandatório, pois poderiam, inclusive, existir à despeito do interesse da organização (Malone, 2002). No entanto, ao longo do tempo, as organizações passaram a usar as comunidades de prática como elementos para facilitar a aprendizagem e compartilhamento de conhecimento de seus funcionários (A. Bourhis \& Dubé, 2010; Liz Lee-Kelley \& Turner, 2017; Wanberg, Javernick-Will, Asce, \& Taylor, 2017)

Tanto as comunidades de conhecimento quanto as comunidades de prática eram circunscritas, inicialmente a grupos de participantes que se reuniam pessoalmente, geralmente ligados a uma empresa. Essas comunidades, aqui chamadas "unialocadas", passaram a ser também utilizadas por conjuntos de empresas, por organizações com equipes deslocadas geograficamente ou mesmo indivíduos que, ao participarem de uma comunidade tinham a possibilidade de trocar conhecimentos, aprender e inovar em conjunto. Tais comunidades, aqui chamadas de "multialocadas", passaram a formar redes, o que trouxe desafios diferentes ao compartilhamento de conhecimento entre seus integrantes.

As práticas de compartilhamento de conhecimento nas comunidades unialocadas têm sido bastante estudadas, contando inclusive com revisões sistemáticas de literatura (Argote, McEvily, \& Reagans, 2003; E. Davenport \& Hall, 2005; Hartung \& Oliveira, 2013; Wang \& Noe, 2010). No entanto, os estudos de comunidades multialocadas têm se concentrado na descrição de suas características, nos promotores e barreiras para o compartilhamento de conhecimento ou ainda, na apresentação de relatos de experiência isoladas de ferramentas e práticas de compartilhamento de conhecimento (Ardichvili, 2008; Hara, Shachaf, \& Stoerger, 2009; Sánchez-Cardona, SánchezLugo, \& Vélez-Gonzalez, 2012; Soekijad, Huis in 't Veld, \& Enserink, 2004). Não foram identificados artigos que façam a integração de tais práticas em comunidades de conhecimento ou CoPs multialocadas. Neste contexto, o presente artigo visa contribuir para a compreensão das práticas de compartilhamento de conhecimento utilizadas em CoPs multialocadas apresentadas na literatura, organizando-as em diferentes dimensões e discutindo sua aplicação como promotoras de compartilhamento de conhecimento.

O artigo está organizado em 5 seções. A primeira com a introdução e uma breve descrição do contexto em que o artigo se sustenta. A segunda, apresenta a metodologia utilizada para o estudo - a revisão sistemática integrativa de literatura - e descreve as etapas que foram cumpridas para a realização deste trabalho. A terceira seção apresenta os dados da revisão sistemática a partir dos temas identificados na análise de dados. A quarta seção discute os resultados, enquanto a quinta apresenta conclusões e sugere encaminhamentos de pesquisas futuras. 


\section{Metodologia}

A metodologia utilizada para a realização deste trabalho é a revisão sistemática integrativa. Tal método de revisão tem por característica o planejamento da revisão de literatura a partir de uma pergunta específica e da utilização de métodos explícitos e sistemáticos para a condução da revisão. Os trabalhos de revisão sistemática apresentam uma metodologia clara e que, caso fosse reproduzida por outros pesquisadores, geraria resultados semelhantes. Por contarem com um processo sistemático e determinado antes do início do processo de seleção de documentos, as revisões sistemáticas reduzem o viés do pesquisador na escolha dos artigos e oportunizam a apresentação de uma visão panorâmica contemplando também as contradições da área (Okoli \& Schabram, 2010; Soares et al., 2014).

Por seguir uma metodologia clara e reprodutível, uma revisão integrativa oferece um panorama amplo e objetivo dos estudos já realizados anteriormente, e permite que se amplie o entendimento do tópico de interesse (Whittemore $\&$ Knafl, 2005). Sua característica particular é que não apenas descreve os estudos, mas também, integra estes conhecimentos, de modo a permitir que novos conhecimentos sejam gerados a partir dos conhecimentos e resultados apresentados em pesquisas anteriores (Botelho, Cunha, \& Macedo, 2011). As etapas para a realização desta revisão integrativa seguem os passos apresentados por Botelho et al. (2011), representados na Figura 1.

Figura 1 - Processo de revisão integrativa

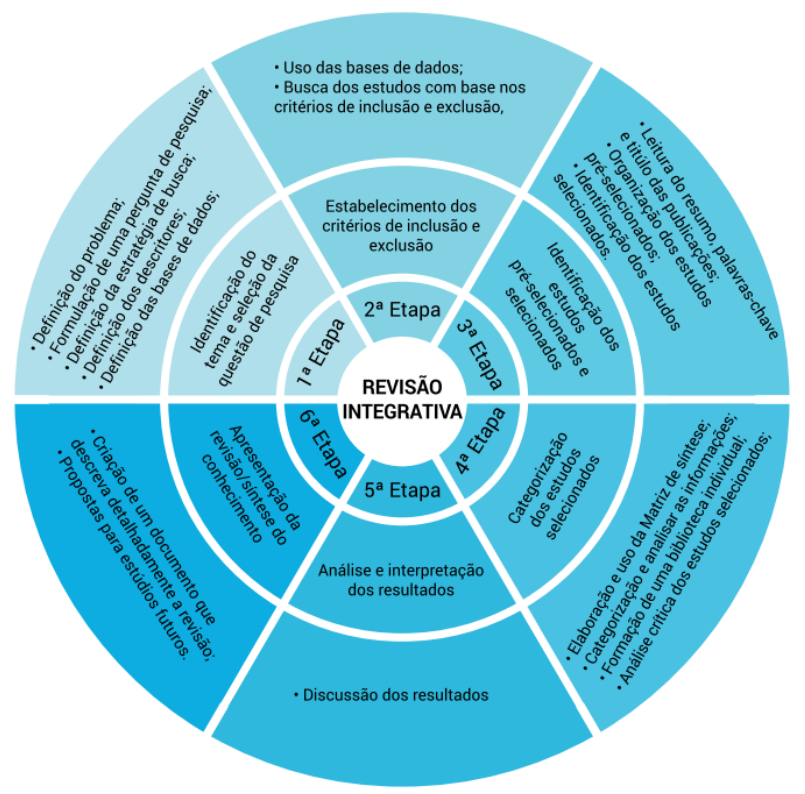

Fonte: (Botelho et al., 2011, p. 129).

O tema definido para esta revisão integrativa foi o compartilhamento de conhecimento em comunidades de conhecimento e a pergunta de pesquisa: "Quais são as práticas de compartilhamento de conhecimento adotadas em comunidades de conhecimento multialocadas"? 
As bases consultadas foram Scopus e Web of Science por serem bases com grande acervo na área de Gestão do Conhecimento e a plataforma Scielo que indexa artigos escritos em língua portuguesa e espanhola a fim de trazer experiências brasileiras de compartilhamento de conhecimento em comunidades de prática multialocadas. Para trazer uma consistência quanto à qualidade dos artigos revisados, a busca considerou apenas artigos científicos com revisão por pares. As palavras-chave inicialmente escolhidas para a busca foram: "knowledge communities/comunidades $d^{*}$ conhecimento"; "knowledge sharing/compartilhamento $d^{*}$ conhecimento"; "knowledge management/gestão d* conhecimento" e "knowledge communities network*/redes de comunidades de conhecimento".

No entanto, o resultado de busca foi nulo e, então, o termo "network*" foi usado em sentido geral. Esta consulta gerou 20 artigos na base Scopus e nenhum artigo em Scielo, o que foi considerado insuficiente. Retirou-se, então, o termo "network*", o que resultou na listagem de 97 artigos para serem analisados na base Scopus e nenhum na base Scielo.

A consulta à base Web of Science foi adicionada depois da leitura completa e análise dos artigos da base Scopus, por entender-se que ainda não havia quantidade suficiente de artigos para a realização da revisão integrativa. A pesquisa na Web of Science resultou em nenhum artigo para ambos os conjuntos de palavras-chave apresentados acima. Como a leitura dos artigos resultantes da busca da base Scopus já havia apresentado o conceito de comunidades de prática como um conceito próximo ao das comunidades de conhecimento, o termo "comunidades de conhecimento" foi substituído por "comunidades de prática" e resultou em 23 artigos.

A etapa de seleção dos artigos para serem analisados contou com os critérios de inclusão e exclusão contidos na tabela 1 .

Tabela 1 - Critérios de inclusão e exclusão da revisão sistemática

\begin{tabular}{|c|c|}
\hline Inclusão & Exclusão \\
\hline - Práticas de compartilhamento de & - Comunidades intraorganizacionais \\
conhecimento; & localizadas em uma única unidade; \\
- Práticas que atendam a barreiras e & - Benefícios das comunidades de prática \\
motivadores de compartilhamento de & ou do conhecimento \\
conhecimento; & - Benefícios do compartilhamento de \\
- Comunidades interorganizacionais; & conhecimento; \\
- Comunidades intraorganizacionais & - Temas ligados à engenharia do \\
dispersas geograficamente; & conhecimento; \\
- Comunidades de prática virtuais; & $\bullet$ Barreiras e motivadores ao \\
& compartilhamento de conhecimento; \\
& $\bullet$ Práticas de identificação, criação, \\
& armazenamento e uso do \\
& conhecimento; \\
& Modelos teóricos de compartilhamento \\
& de conhecimento. \\
\hline
\end{tabular}

Fonte: Dos autores. 
Nesta etapa, foram analisados os títulos e resumos de todos os artigos da lista da base Scopus e foram selecionados 28 artigos para a leitura em detalhe. Desta lista, 11 artigos não puderam ser acessados. Os 17 artigos restantes foram lidos e, destes, foram identificados 11 artigos que atendiam aos critérios de inclusão adotados.

Dos 23 artigos da base Web of Science, foram selecionados 13 artigos na primeira análise de critério. Destes, 6 textos faziam parte da lista de artigos da base Scopus, já analisados. Dos 7 artigos restantes, 4 foram adicionados à lista de artigos a serem revisados que, adicionados aos 11 artigos selecionados da base Scopus, geraram uma lista de 15 artigos, que formam a base para esta revisão integrativa. A figura 2 representa este processo.

Figura 2 - Processo de busca sistemática

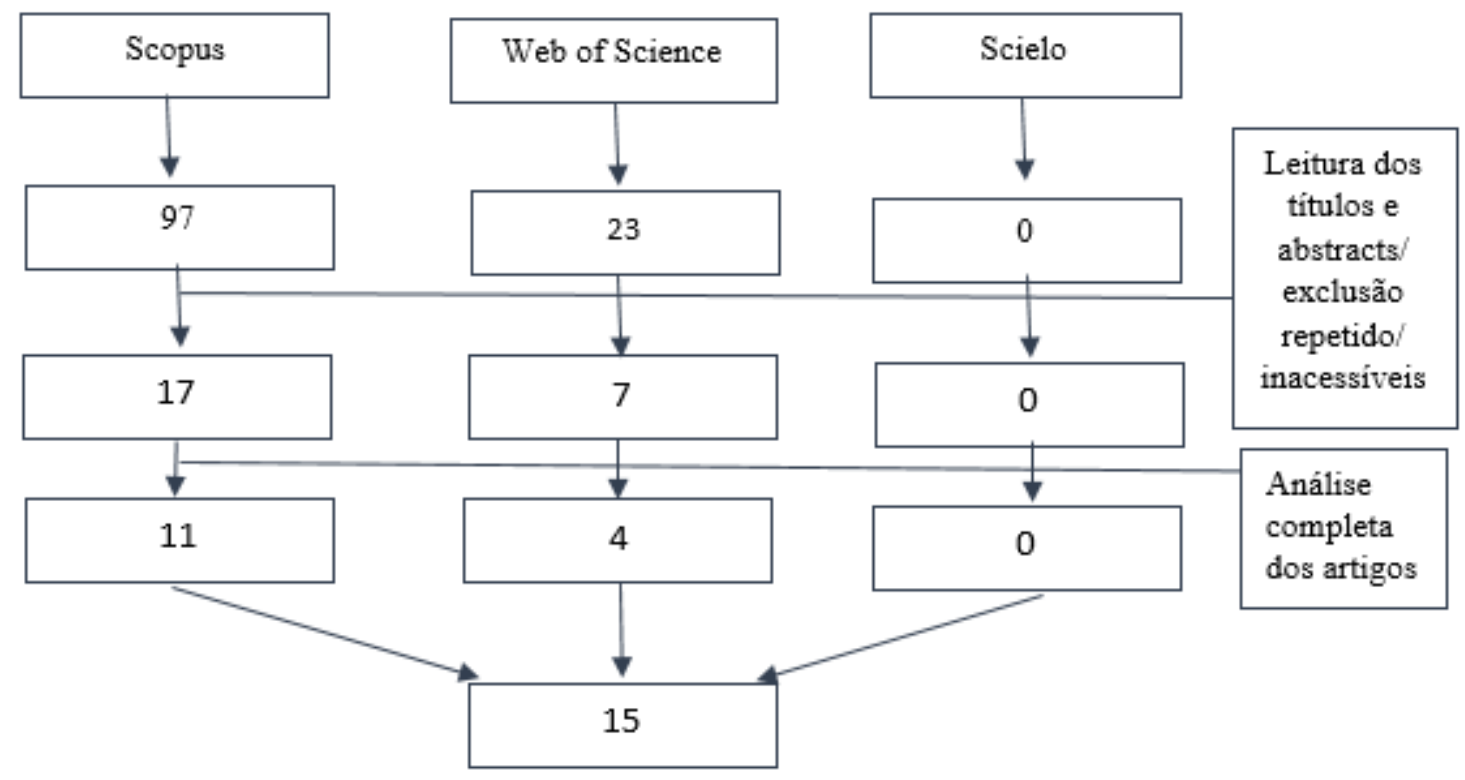

Fonte: Dos autores.

Os artigos finais foram então abordados com a utilização do método de análise temática indutiva, com a identificação de padrões emergentes das práticas de compartilhamento de conhecimento reportadas (Braun \& Clarke, 2012). As práticas de cada artigo foram codificadas e organizadas em quatro temas, os que serão o fio condutor da análise e discussão dos resultados, apresentados a seguir.

\section{Análise e discussão de resultados}

A análise temática indutiva dos dados levou à identificação de quatro grandes conjuntos de práticas no que diz respeito ao compartilhamento de conhecimento em Comunidades de Prática (CoPs) multi-alocadas. Tais práticas dizem respeito às seguintes dimensões: 1) contexto em que o compartilhamento de conhecimento acontece, 2) práticas de compartilhamento de conhecimento 
propriamente ditas, 3) práticas que favorecem a conexão entre as pessoas para que compartilhem conhecimento e, por fim, 4) práticas de gestão e governança, que dão as bases para que o processo de compartilhamento de conhecimento se realize e seja sustentado.

As práticas ligadas ao contexto onde as relações e encontros acontecem serão discutidas sob o tema "Lugar agregador"; as práticas de compartilhamento de conhecimento serão tratadas no tema "De tomadores a compartilhadores de conhecimento". Por sua vez, as práticas que oportunizam as conexões sociais necessárias ao compartilhamento estão contidas no tema "Promoção de conexões". Finalmente, as práticas que tratam da estruturação, implantação e sustentação do compartilhamento de conhecimento nas CoPs multialocadas estão reunidas sob o tema "Implantação e sustentação". A distribuição dos artigos revisados nessas categorias está expressa na Tabela 2.

Tabela 2 - Dimensões e práticas de compartilhamento de conhecimento identificadas na literatura

\begin{tabular}{|c|c|c|c|}
\hline Temáticas & Categorias & Práticas apontadas & \\
\hline \multirow[t]{2}{*}{ Lugar agregador } & $\begin{array}{l}\text { Encontros face a } \\
\text { face }\end{array}$ & $\begin{array}{l}\text { Visitas, conversas, grupos de } \\
\text { aprendizagem, reuniões } \\
\text { Encontros anuais } \\
\text { Almoços mensais } \\
\text { Eventos presenciais para } \\
\text { lançamento de iniciativas }\end{array}$ & $\begin{array}{l}\text { (Apostolou, Mentzas, Baraboutis, \& Papadopoulou, } \\
\text { 2004; Hamunen, Virkkula, Hujala, Hiedanpaa, \& } \\
\text { Kurttila, 2015) } \\
\text { (D.E. Topousis, Dennehy, \& Lebsock, 2012) } \\
\text { (Ho \& Kuo, 2013) } \\
\text { (Davis et al., 2010) }\end{array}$ \\
\hline & Portais & $\begin{array}{l}\text { Portais com múltiplas } \\
\text { funcionalidades } \\
\text { Portais simples }\end{array}$ & $\begin{array}{l}\text { (Amal Al-Rasheed \& Berri, 2016; Antonacci, } \\
\text { Fronzetti Colladon, Stefanini, \& Gloor, 2017; } \\
\text { Apostolou et al., 2004; Anne Bourhis \& Dubé, 2010; } \\
\text { Cheung, Lee, \& Lee, 2013; Davis et al., 2010; Ho \& } \\
\text { Kuo, 2013; L. Lee-Kelley \& Turner, 2017; S. L. Pan } \\
\text { \& Leidner, 2003; D.E. Topousis et al., 2012) } \\
\text { (Julian M. Sims, 2018) }\end{array}$ \\
\hline $\begin{array}{l}\text { De tomadores a } \\
\text { compartilhadores } \\
\text { de conhecimento }\end{array}$ & $\begin{array}{l}\text { Acessar } \\
\text { conhecimento }\end{array}$ & $\begin{array}{l}\text { Aulas/palestras } \\
\text { Encontros temáticos } \\
\text { Webconferências }\end{array}$ & $\begin{array}{l}\text { (Hamunen et al., 2015; S. L. Pan \& Leidner, 2003) } \\
\text { (Apostolou et al., 2004; Ho \& Kuo, 2013; L. Lee- } \\
\text { Kelley \& Turner, 2017) } \\
\text { (Bourdon, Kimble, \& Tessier, 2015; Anne Bourhis } \\
\& \text { Dubé, 2010; S. L. Pan \& Leidner, 2003; D.E. } \\
\text { Topousis et al., 2012) } \\
\text { (Apostolou et al., 2004; Cheung et al., 2013; L. Lee- } \\
\text { Kelley \& Turner, 2017) }\end{array}$ \\
\hline
\end{tabular}




\begin{tabular}{|c|c|c|c|}
\hline & & $\begin{array}{l}\text { Biblioteca de documentos } \\
\text { Compartilhamento } \\
\text { experiências/casos/histórias de } \\
\text { Notícias } \\
\text { Perguntas e respostas } \\
\begin{array}{l}\text { Oferta de materiais para uso } \\
\text { profissional }\end{array}\end{array}$ & $\begin{array}{l}\text { (Amal Al-Rasheed \& Berri, 2016) L. Lee-Kelley \& } \\
\text { Turner, 2017; S. L. Pan \& Leidner, 2003) } \\
\text { (Antonacci et al., 2017; Bourdon et al., 2015; L. Lee- } \\
\text { Kelley \& Turner, 2017) } \\
\text { (Antonacci et al., 2017; Bourdon et al., 2015) } \\
\text { (J.M. Sims, 2018; D.E. Topousis et al., 2012) } \\
\text { (Amal Al-Rasheed \& Berri, 2016; Cheung et al., } \\
\text { 2013; Daria E. Topousis et al., 2012) }\end{array}$ \\
\hline & $\begin{array}{l}\text { Oferecer } \\
\text { conhecimento }\end{array}$ & $\begin{array}{l}\text { Blogs } \\
\text { Disponibilização de materiais para } \\
\text { reuso } \\
\text { Espaço para feedback em materiais } \\
\text { compartilhado }\end{array}$ & $\begin{array}{l}\text { (J.M. Sims, 2018; D.E. Topousis et al., 2012) } \\
\text { (Amal Al-Rasheed \& Berri, 2016; Davis et al., 2010) } \\
\text { (Cheung et al., 2013; Davis et al., 2010) }\end{array}$ \\
\hline & $\begin{array}{l}\text { Compartilhamento } \\
\text { mútuo }\end{array}$ & $\begin{array}{l}\text { Lista de contatos } \\
\text { Fórum } \\
\begin{array}{l}\text { E-mails, mensagens, perguntas e } \\
\text { respostas } \\
\text { Teleconferência }\end{array}\end{array}$ & $\begin{array}{l}\text { (D.E. Topousis et al., 2012) } \\
\text { (Antonacci et al., 2017; Hamunen et al., 2015; L. } \\
\text { Lee-Kelley \& Turner, 2017; D.E. Topousis et al., } \\
\text { 2012) } \\
\text { (S. L. Pan \& Leidner, 2003; J.M. Sims, 2018) } \\
\text { (S. L. Pan \& Leidner, 2003) }\end{array}$ \\
\hline $\begin{array}{l}\text { Promovendo } \\
\text { conexões }\end{array}$ & & $\begin{array}{l}\text { Rede Social } \\
\text { Encontros pessoais, eventos } \\
\text { Ferramentas de colaboração } \\
\text { "Pertença a essa comunidade" } \\
\text { Incentivos }\end{array}$ & $\begin{array}{l}\text { (Y. Pan et al., 2015; Wanberg et al., 2017) } \\
\text { (Hamunen et al., 2015; Wanberg et al., 2017) } \\
\text { (Anne Bourhis \& Dubé, 2010) } \\
\text { (D.E. Topousis et al., 2012) } \\
\text { (Bourdon et al., 2015; Anne Bourhis \& Dubé, 2010; } \\
\text { Cheung et al., 2013; Ho \& Kuo, 2013) } \\
\text { (Davis et al., 2010; Y. Pan et al., 2015; D.E. } \\
\text { Topousis et al., 2012) } \\
\text { (J.M. Sims, 2018; D.E. Topousis et al., 2012; } \\
\text { Wanberg et al., 2017) }\end{array}$ \\
\hline $\begin{array}{l}\text { Implantar } \\
\text { sustentar }\end{array}$ & Liderança & Liderança formal & $\begin{array}{l}\text { (Bourdon et al., 2015; L. Lee-Kelley \& Turner, } \\
\text { 2017; S. L. Pan \& Leidner, 2003; D.E. Topousis et } \\
\text { al., 2012) }\end{array}$ \\
\hline
\end{tabular}




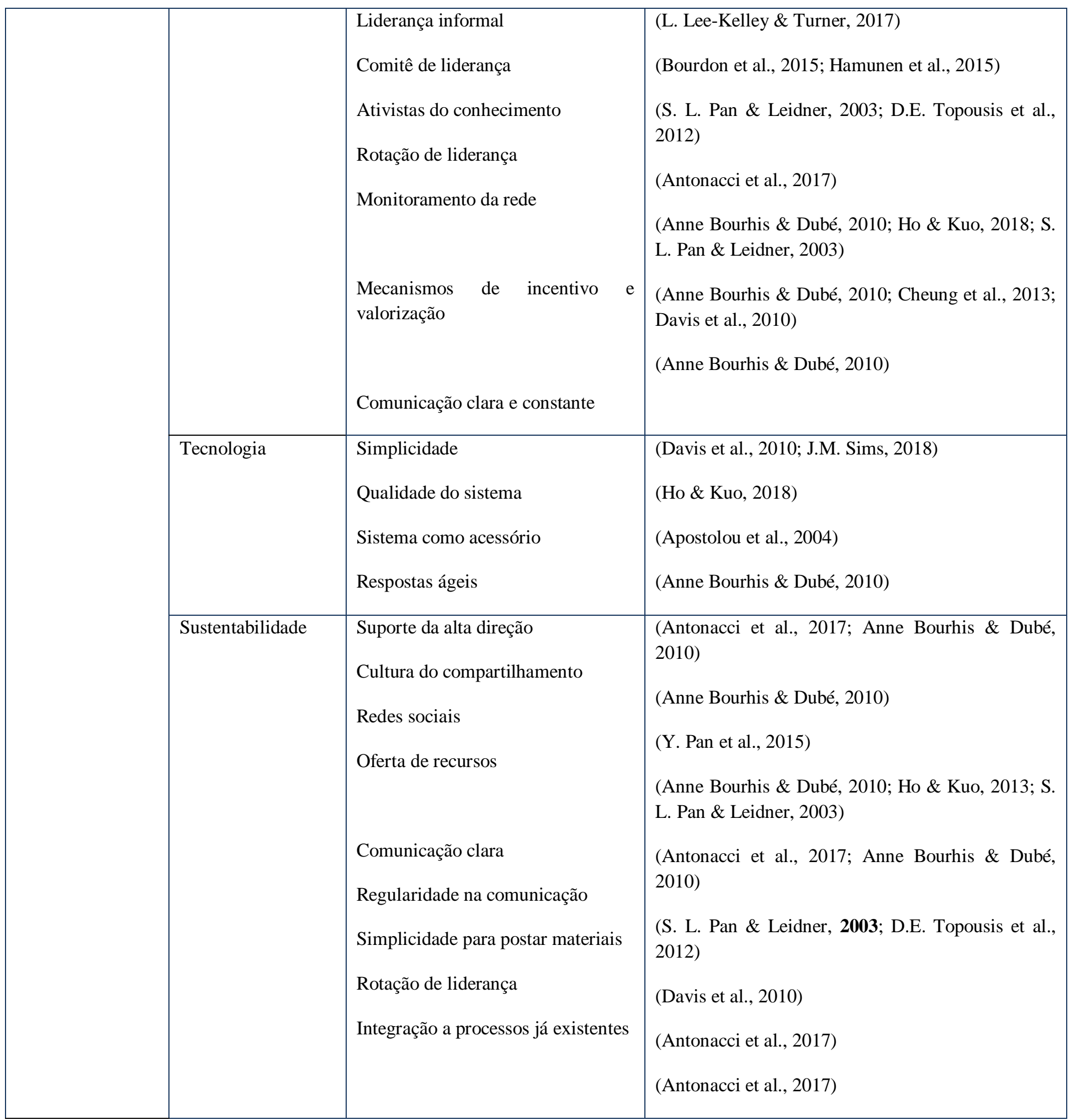

Fonte: Dos autores.

Lugar agregador

O conhecimento precisa de um espaço para ser compartilhado. As práticas descritas nos artigos revisados demonstram que esse espaço pode ser físico ou virtual e que precisa ser arquitetado 
de modo a oferecer o contexto e os meios para que o conhecimento seja compartilhado. Estes meios podem ser diretos, através do contato entre as pessoas, ou indiretos, por meio do acesso ao conhecimento disponibilizado em documentos, bases de dados ou outros materiais (Piedade, Alcará, Chiara, Tomaél, \& Rodrigues, 2009).

Os encontros face a face têm papel importante no compartilhamento do conhecimento e sustentam as práticas de compartilhamento em comunidades diversas, tais como em uma comunidade de prática formada por proprietários de florestas na Finlândia, apresentada por Hamunen et al. (2015) e na comunidade de aprendizagem de empresas austríacas, reportadas por Apostolou et al (2003). Nesses dois exemplos, os encontros viabilizam a realização de visitas, conversas, participação em atividades de discussão de temas de interesse, treinamentos conjuntos, construção de grupos de aprendizagem e também a formação de relações de liderança dentro da comunidade. Os encontros também têm a função de estabelecer contatos informais para que a troca de conhecimento e a cocriação de soluções comuns possa acontecer. Deste modo, são contexto tanto para o compartilhamento de conhecimento explícito quanto de conhecimento tácito (Polanyi, 1966). Encontros face a face também são práticas usadas em comunidades que têm o espaço virtual como sua principal arena de troca. Nesse caso, os encontros têm função complementar ao espaço virtual, como em encontros anuais dos participantes das Comunidades de Práticas (CoPs) da NASA (Daria E. Topousis, Dennehy, \& Lebsock, 2012) ou nos almoços mensais da comunidade de profissionais de recursos humanos reportados por Ho e Kuo (2013). Estes momentos fortalecem as conexões e também oportunizam que novas conexões se formem e sejam levadas para o mundo virtual (Wanberg et al., 2017). Eventos presenciais são também usados para o lançamento de comunidades e portais com o objetivo de apresentar e promover o engajamento inicial das equipes (Davis et al., 2010). A proximidade física e informalidade destes momentos colaboram para que as pessoas se conheçam e construam vínculos. Deste modo, contribuem positivamente para o compartilhamento do conhecimento a partir da construção das relações de confiança necessárias para que os indivíduos estejam motivados para fazê-lo (T. H. Davenport \& Prusak, 1998; Ipe, 2004; Piedade et al., 2009).

No entanto, o espaço virtual parece ser a grande arena de encontro e compartilhamento de conhecimento utilizado pelas comunidades que estão espalhadas geograficamente. As comunidades se valem de portais como o local agregador dos relacionamentos entre seus membros e neles depositam conteúdos, oferecem ferramentas de colaboração e comunicação entre seus membros ou, ainda, mantém a comunidade informada a respeito de eventos (Amal Al-Rasheed \& Berri, 2016; Antonacci et al., 2017; Apostolou et al., 2004; A. Bourhis \& Dubé, 2010; Cheung et al., 2013; Davis et al., 2010; Ho \& Kuo, 2013; L. Lee-Kelley \& Turner, 2017; S. L. Pan \& Leidner, 2003; Julian M. Sims, 2018; D.E. Topousis et al., 2012).

Os portais podem ter interações síncronas ou assíncronas, podem ser grandes, com muitas seções, tais como os disponibilizados para as CoPs de companhias (S. L. Pan \& Leidner, 2003; D.E. 
Topousis et al., 2012) ou podem ser muito simples, contendo apenas espaço para perguntas, endereços de e-mails e blogs, como descritos na comunidade de profissionais de saúde apresentada por Sims (2018). Um aspecto importante é que sejam amistosos, correspondam às necessidades da comunidade e sejam flexíveis (Davis et al., 2010; S. L. Pan \& Leidner, 2003).

\section{De tomadores a compartilhadores de conhecimento}

As práticas e ferramentas de compartilhamento de conhecimento descritas nos artigos revisados foram organizadas em três categorias, que correspondem a diferentes tipos de motivação, níveis de participação e compartilhamento: ganhar conhecimento, oferecer conhecimento e trocar conhecimentos.

\section{$\underline{\text { Acessar conhecimento }}$}

Uma motivação importante para a participação em CoPs ou comunidades de aprendizagem é a possibilidade de aprender, acessar informações e conhecer novas pessoas e possibilidades de atuação (Piedade et al., 2009). Ganhar conhecimento foi apontado como o primeiro nível de busca de participação na CoP de gerentes de projetos da HP, descrita por Lee- Lelley e Turner (2016). Nesta comunidade, essa foi a motivação inicial reportada por seus participantes para a participação na comunidade de prática. A motivação inicial dos profisssionais estudados foi buscar informações atualizadas de mercado ou soluções prontas de como conduzir projetos.

Só depois de um período de tempo de funcionamento da $\mathrm{CoP}$, a partir da construção de laços de confiança e reciprocidade, é que as questões discutidas passaram de táticas e operacionais para questões mais estratégicas sobre experiências e soluções compartilhadas.

Levando em consideração a participação baseada na necessidade de buscar conhecimento, identifica-se que há uma oferta consistente de modalidades de conteúdo pelas comunidades, no formato de aulas, palestras, encontros temáticos, webconferências, bibliotecas de documentos, espaço para compartilhamento de histórias e truques de ofício, registro de perguntas e respostas, melhores práticas, recursos e materiais de trabalho (Amal Al-Rasheed \& Berri, 2016; Apostolou et al., 2004; Bourdon et al., 2015; Cheung et al., 2013; Davis et al., 2010; Hamunen et al., 2015; Liz Lee-Kelley \& Turner, 2017; S. L. Pan \& Leidner, 2003; J.M. Sims, 2018; Daria E. Topousis et al., 2012). Independentemente da modalidade, Topousis et al. (2013) destacam que o conteúdo oferecido deve ser relevante e atual. Sims (2018) completa afirmando que o conteúdo compartilhado precisa ajudar o profissional a melhorar sua prática profissional e Al-Rashed e Berri (2017) reforçam que os conteúdos precisam facilitar a vida dos membros, adotando estratégias de oferta de conteúdo de acordo com o seu perfil ou oferecendo possibilidade de reuso de materiais disponibilizados. Para exemplificar a importância da relevância de conteúdo para a participação reiterada dos membros de 
uma comunidade, destaca-se a decisão das equipes das CoPs da NASA de lançarem seu portal apenas quando tiveram uma quantidade suficiente de conteúdos postados (D.E. Topousis et al., 2012).

\section{Oferecer conhecimento}

Para que uma rede atinja o objetivo de que seus membros ofertem conhecimento para os demais membros da comunidade é essencial que haja práticas e ferramentas para tal. As práticas virtuais apresentadas nos artigos são o blog, webconferências realizadas por membros da comunidade, wikis e plataformas para compartilhamento de artigos, apresentação de melhores práticas ou de materiais usados em projetos (Davis et al., 2010; Liz Lee-Kelley \& Turner, 2017; J.M. Sims, 2018; D.E. Topousis et al., 2012). Nas redes que se valem dos encontros face a face, a contação de histórias, as apresentações de contéudo e relatos de caso por membros da comunidade são exemplos de práticas para o compartilhamento de conhecimento (Apostolou et al., 2004; Hamunen et al., 2015).

Davis et al. (2010) destacam que o compartilhamento de conhecimento pode ser facilitado pelos processos e pela tecnologia. Seu artigo relata a experiência com o compartilhamento de conhecimento entre professores universitários. Orientam que os passos para se fazer o envio de um material devem ser poucos, com necessidade mínima de descritores ou de etapas para identificar o material. Argumentam que quando a quantidade de etapas para disponibilizar materiais e informações é muito grande, a intenção de compartilhar conhecimento diminui. Ainda sugerem que haja atenção ao número de campos a serem preenchidos pelos membros ao compartilharem conhecimento, indicando o limite de sete.

No entanto, a oferta de ferramentas para compartilhamento de conhecimento não é suficiente para que ele ocorra. Práticas que tratem dos aspectos motivacionais para o compartilhamento de conhecimento também são importantes. Esta questão é tratada por alguns dos artigos revisados, a partir de práticas que estimulem o compartilhamento inicial e recorrente de conhecimento. Para Cheung et al (2013) um elemento a ser tratado para promover o compartilhamento de conhecimento é trabalhar a crença daquele que detém conhecimento de que é importante que ele seja compartilhado e que tem valor para outros membros da comunidade. Os autores discutem que o sentimento de autoeficácia é relevante na decisão de continuidade de compartilhamento de conhecimento e usam a definição de Bandura (1986) para explicar que autoeficácia é a "crença das pessoas sobre sua capacidade de produzir níveis designados de desempenho que exerçam influência sobre eventos que afetam sua vida" (p. 71). Neste sentido, sugerem que sejam incluídos mecanismos de feedback dos projetos compartilhados tais como comentários, avaliação de reação ou algo que possa oferecer uma medida do impacto de sua ação àqueles que contribuem com seu conhecimento. A possibilidade da identificação de reuso de materiais e feedbacks sobre os materiais postados como pontuação também 
são apontados como sugestões por Al-Rasheed e Berri (2016). Destaca-se, no entanto, que o uso de incentivos para fomentar o compartilhamento é tema que tem posições diversas. Incentivos materiais tais como os propostos pelos autores não foram percebidos como geradores de impacto na decisão de compartilhamento de conhecimento em estudo realizado em comunidade de profissionais de recursos humanos, tendo sido superados por incentivos sociais, que denotam senso de pertencimento ou incentivos relacionados a atividades a serem desempenhadas na comunidade (Ho \& Kuo, 2013).

Davis et al (2010) também discutem o tema da autoeficácia, afirmando que é importante esclarecer para os membros da comunidade que não precisam compartilhar trabalhos perfeitos, já que, no caso da rede professores que apresentaram os materiais compartilhados costumam ser documentos dinâmicos. Para isso, sugerem que seja oferecida autonomia para os compartilhadores na definição da audiência para quem seus materiais ficarão disponíveis.

O senso de comunidade é outro elemento que pode auxiliar na promoção do compartilhamento de conhecimento. O uso de perfis é apontado como uma estratégia que pode colaborar, já que dá identidade às pessoas. Por outro lado, esse tema também tem posição diversa apontada pelos próprios autores, tendo em vista que há pessoas que não apreciam a exposição de informações pessoais (Davis et al., 2010).

\section{Compartilhamento mútuo}

A interação de forma produtiva nas CoPs deve se estabelecer no sentido de possibilitar conversações que oportunizem compartilhamento mútuo de conhecimento entre seus membros pois a interação possibilita a aprendizagem e também a coconstrução de conhecimentos (Wenger \& Snyder, 2000). As conversações entre membros das comunidades estudadas são oportunizadas de diversas maneiras. Nas comunidades que se valem de encontro face a face, as práticas adotadas são os fóruns, conversas informais, trabalhos conjuntos para a solução de problemas comuns e também trabalhos em times de aprendizagem (Apostolou et al., 2004; Hamunen et al., 2015).

Nas comunidades virtuais, trocas de e-mails, perguntas postadas no portal, discussões de caso, teleconferências e fóruns com discussão síncrona e assíncrona são práticas adotadas pelas comunidades estudadas. As listas de contato têm papel importante nas conversações em redes virtuais, pois auxiliam na identificação de especialistas em assuntos para serem acessados pelos membros da comunidade e, assim, são iniciadoras de movimentos de compartilhamento de conhecimento (Antonacci et al., 2017; Davis et al., 2010; Liz Lee-Kelley \& Turner, 2017; J.M. Sims, 2018; D.E. Topousis et al., 2012; Wanberg et al., 2017). O e-mail é descrito como uma ferramenta importante. No caso da rede de telemedicina reportada por Sims (2018), por exemplo, grande parte das trocas são feitas por e-mail. Nas comunidades de prática da NASA, os fóruns virtuais têm 
impacto limitado, com os membros fazendo contato inicial por meio deles, e continuando por intermédio da troca de mensagens de e-mail (D.E. Topousis et al., 2012).

\section{Promovendo conexões}

A interação social é primordial para o compartilhamento de conhecimento e estabelecimento de conexões entre os membros de uma comunidade é chave para que o conhecimento flua entre seus membros (Ipe, 2004). Os artigos revisados apresentaram uma série de práticas com o objetivo de promover o encontro e compartilhamento de conhecimento entre os participantes das CoPs multialocadas. Também, há uma preocupação com a manutenção da motivação dos membros das comunidades para que continuem a compartilhar conhecimento e assim possam estabelecer relacionamento por tempo suficiente de modo a trazer profundidade à troca de conhecimentos (Piedade et al., 2009).

As práticas para promoção de interação social adotadas pelas CoPs multialocadas diferem de acordo com a natureza do contexto de troca que têm. As redes que se valem de encontros presenciais, têm na presença física uma vantagem, já que a proximidade tende a nutrir as conexões (Wanberg et al., 2017). As redes virtuais, por sua vez, precisam encontrar caminhos para que as conexões sejam estabelecidas e nutridas.

Nas comunidades virtuais as discussões online não acontecem de imediato e tendem a acontecer apenas depois que as pessoas desenvolvem sua rede de conexões virtuais (D.E. Topousis et al., 2012). Aproximar os membros e auxiliá-los a criar relações de reciprocidade e interação social são, portanto, tarefas importantes nestas comunidades. Bourdon et al (2015) reportaram o uso de web-encontros organizados pela liderança da CoP para a apresentação e discussão de boas práticas, de histórias e experiências entre os membros. Quando possível, encontros sociais também são usados para estabelecer conexões entre os membros de CoPs de modo a alimentar as interações na rede virtual (Ho \& Kuo, 2013).

Pan et al. (2015) defendem a integração de redes sociais a sistemas de gestão do conhecimento. Afirmam que as redes sociais colaboram para a promoção de troca de conhecimento entre as pessoas, pois trabalham em torno do conceito de "amigos" para organizar as redes de contato. Nesta abordagem, as pessoas deixam de se conectar através de temas e passam a se conectar com pessoas, que deixam de ser "estranhos" para tornarem-se "amigos". Sua pesquisa aponta que as trocas de conhecimento entre amigos foram maiores e que as conexões estabelecidas foram menos suscetíveis a se quebrarem.

As práticas promotoras de novas conexões em CoPs virtuais identificadas são as listas de contatos, as chamadas do tipo "Pertença a essa comunidade", as listas de localização de experts e os perfis individuais dos membros (Julian M. Sims, 2018; D.E. Topousis et al., 2012). As áreas para 
feedback nos materiais postados também são usadas como canais para iniciar conexões e colaborar para o fortalecimento de conexões ao longo do tempo (Amal Al-Rasheed \& Berri, 2016; Cheung et al., 2013; Davis et al., 2010). As CoPs que contam com encontros face a face, por sua vez, viabilizam novas conexões com a organização de encontros temáticos, visitas técnicas, excursões, encontros sociais, treinamentos em questões de interesse mútuo e grupos de aprendizagem (Apostolou et al., 2004; Hamunen et al., 2015; Ho \& Kuo, 2013)

Wanberg et al. (2017) identificaram que a maioria das conexões estabelecidas nas comunidades de práticas estudas por seu grupo havia sido resultado da atividade operacional normal da empresa - físicas ou virtuais. Os autores identificaram quatro formas de início de conexão, com o seguinte percentual de ocorrência : 44\% pela estrutura hierárquica da empresa (algum trabalho em conjunto designado); $37 \%$ por oportunidade (eventos empresariais, localização de espaços de trabalho); $13 \%$ por relação social (apresentação por colegas e $6 \%$ por meios não pessoais (organogramas, listas de contatos, perguntas no portal). Sugerem um modelo de atuação da empresa no sentido de fomentar novas conexões tanto pela estrutura hierárquica quanto pela criação de oportunidades de conexão entre seus membros.

\section{Implantar e sustentar}

A criação de um ambiente em que o conhecimento seja compartilhado também diz respeito ao uso de práticas de gestão organizacional para que tal ambiente seja implantado e tenha perenidade suficiente para trazer benefícios aos membros e suas organizações. Neste sentido, as práticas discutidas nos artigos revisados foram organizadas nos seguintes temas: liderança, tecnologia e sustentabilidade.

\section{$\underline{\text { Liderança }}$}

A implantação de uma cultura de compartilhamento demanda uma comunicação clara e contínua da alta direção da empresa ou de uma comunidade. Ela é necessária para instalar a força motriz para as mudanças necessárias (A. Bourhis \& Dubé, 2010). Na constituição de uma comunidade de prática, a alta liderança precisa prever suporte em quatro esferas, segundo Bourhis e Dubé: a) na emissão de uma mensagem clara e homogênea de suporte e valorização da CoP, b) na oferta de recursos adequados para a realização de suas atividades, c) no monitoramento da liderança a fim de que ofereça respostas ágeis aos membros e d) na previsão de incentivos para a participação.

A liderança é um aspecto essencial a ser observado na implantação e operação de uma comunidade de prática, de conhecimento ou de aprendizagem. A definição de uma liderança formal faz parte das práticas descritas em vários dos artigos revisados (Bourdon et al., 2015; A. Bourhis \& 
Dubé, 2010; Cheung et al., 2013; Liz Lee-Kelley \& Turner, 2017; S. L. Pan \& Leidner, 2003; D.E. Topousis et al., 2012).

No entanto, a liderança informal ou compartilhada também é citada em alguns dos artigos. Bourdon et al (2015) descrevem a prática de liderança a partir de um comitê central da CoP. Tal comitê tem sua composição regularmente alterada, com seus membros designados a partir de sua participação na comunidade. A identificação de tais membros é feita com a utilização de indicadores resultantes de critérios pré-estabelecidos pela própria comunidade. Segundo os autores, a troca regular de lideranças distribui o poder na comunidade e fortalece a participação de seus membros. Lee-Kelley e Turner (2017) descrevem uma prática de liderança mista com uma formal que tem como um de seus objetivos constituir e nutrir um núcleo de lideranças voluntárias. Tal prática tem objetivo de facilitar a conexão intraorganizacional em uma $\mathrm{CoP}$ estabelecida entre gerentes de projetos de uma companhia multinacional cujos membros estão espalhados em diversos pontos do globo. Antonacci et al. (2017), por sua vez, destacam que a estrutura centralizada e a rotação de liderança são determinantes para o crescimento de uma comunidade de prática virtual.

\section{$\underline{\text { Tecnologia }}$}

A tecnologia é apresentada como elemento essencial para que as CoPs multialocadas possam existir (S. L. Pan \& Leidner, 2003). É ela que possibilita as conexões dos distantes e oferece as ferramentas que possibilitam o acesso ao conhecimento, seu compartilhamento e as conexões entre as pessoas. Práticas descritas no uso da tecnologia nos artigos convergem para o conceito da simplicidade de uso.

Davis et al. (2010) reforçam que a tecnologia deve ter uma interface amigável, ser de fácil utilização e que deve usar ferramentas que diminuam o trabalho de seus membros ao catalogarem suas atividades. Em seu estudo, identificam que o número de campos a serem preenchidos é inversamente proporcional à manutenção do interesse em compartilhar conhecimento e indicam que o número máximo de campos a serem preenchidos com tags e descritores do conhecimento a ser compartilhado é sete. No que diz respeito a estes descritores, os autores reportam que são importantes para oportunizar buscas assertivas e, portanto, são parte importante de um sistema de compartilhamento de conhecimento. Adicionalmente, reportam que espaços para comentários da comunidade e também a indicação de reuso dos conteúdos postados são outros recursos tecnológicos que, quando agregados à plataforma de compartilhamento de conhecimento, contribuem para a manutenção do interesse em compartilhá-lo.

As ferramentas de busca devem responder ao perfil e necessidades dos usuários. Neste sentido, práticas de indicação de conteúdos para os participantes da comunidade podem ser viabilizadas pela tecnologia (Amal Al-Rasheed \& Berri, 2016). Também, sistemas de redes sociais 
podem colocar pessoas com interesses similares em contato e, assim, nutrir conversações que levem a compartilhamento de conhecimentos (Y. Pan et al., 2015).

A agilidade na resposta às necessidades da comunidade pela equipe de sistemas é uma condição para que um sistema tenha adesão (A. Bourhis \& Dubé, 2010). No entanto, resultados do estudo apresentado por Ho e Kuo (2013) indicam que a qualidade do serviço prestado pela equipe responsável pelo sistema tem menor influência no compartilhamento de conhecimento do que qualidade do sistema (facilidade de uso, confiabilidade, interface amistosa) e a qualidade de informação (conteúdo correto, de fácil entendimento, relevante, completo, oportuno e útil).

Os artigos revisados apresentam sistemas em diferentes níveis de complexidade e sofisticação. Há os sistemas com portais bastante elaborados, com várias áreas de conteúdo, bancos de dados de casos, blogs, ferramentas para identificação de experts e espaço para mensagens, conversas e teleconferências, (Davis et al., 2010; S. L. Pan \& Leidner, 2003; Daria E. Topousis et al., 2012). Assim como há exemplo de sistema simples que se baseia na oferta de conteúdo através de blog, em listas de experts e na troca de e-mails (Julian M. Sims, 2018).

\section{$\underline{\text { Sustentabilidade }}$}

Tão importante quanto iniciar uma cultura e prática de compartilhamento de conhecimento é sustentá-la. As práticas apontadas nos textos, no sentido de trazer sustentabilidade para a cultura de compartilhamento, são o suporte da alta liderança, a comunicação clara de valorização do compartilhamento de conhecimento, a oferta de recursos financeiros, de tempo e esforço suficientes para que as ações da $\mathrm{CoP}$ se realizem, e o monitoramento das ações das lideranças para que os temas sejam tratados com prontidão (A. Bourhis \& Dubé, 2010; Ho \& Kuo, 2013; S. L. Pan \& Leidner, 2003).

A regularidade nas ações da comunidade também é essencial com a manutenção constante da operação do portal e das atividades de relacionamento da rede (S. L. Pan \& Leidner, 2003; D.E. Topousis et al., 2012). Também, a relevância da comunidade para seus usuários é componente essencial para que ela se sustente (Julian M. Sims, 2018). A simplicidade de uso dos sistemas e a integração das atividades da comunidade aos processos organizacionais, de modo a reduzir ao máximo retrabalho são outras práticas que colaboram para que a cultura de compartilhamento seja sustentável (Apostolou et al., 2004; Davis et al., 2010). Do mesmo modo, a rotação de liderança, o uso de linguagem menos complexa e a centralidade da liderança nos processos de trocas sociais na rede são práticas que colaboram para que as comunidades cresçam e suas ações sejam sustentáveis (Antonacci et al., 2017). Por fim, práticas ligadas ao tratamento dos motivos pelos quais as pessoas compartilham seu conhecimento, tais como, o uso do conceito de autoeficácia e reciprocidade são 
relevantes não só para a construção da cultura de compartilhamento, mas também, para sua manutenção (Cheung et al., 2013; Davis et al., 2010).

\section{Discussão dos resultados}

As Comunidades de Prática (CoPs) multialocadas estudadas valem-se de uma série de práticas para que o conhecimento seja compartilhado. Baseiam-se no conceito de que a aprendizagem é um fenômeno social e que, portanto, à medida que as pessoas tiverem a oportunidade de se integrarem em ambientes em que a confiança seja estabelecida, elas se sentirão confortáveis para compartilhar conhecimento tácito e explícito (Li \& Gao, 2003; Wenger \& Snyder, 2000). As práticas descritas na seção anterior descrevem diferentes atividades e abordam diferentes fatores das comunidades que podem ser apoiadores e promotores do compartilhamento de conhecimento. Aqui, serão discutidas de modo integrado, para oferecer uma síntese dos conhecimentos construídos na seção anterior.

Todas as práticas apresentadas acontecem em um lugar, chamado aqui de "lugar agregador". Tal denominação remete ao conceito de "ba", que é caracterizado como um lugar compartilhado em que relações podem emergir (Nonaka \& Konno, 1998). É nesse conceito que os espaços das comunidades precisam ser considerados: como espaços viabilizadores das relações e da criação de conhecimento. Do contrário, serão apenas pontos de encontro ou fontes de consulta. A concepção destes espaços sob o ponto de vista das relações que promovem e do conhecimento que pode ser criado, a partir do compartilhamento de conhecimentos dos participantes, é o que fará tais espaços serem enriquecedores para seus membros.

Neste sentido, os líderes têm papel relevante ao ocuparem a posição de organizadores destes locais agregadores. Na estruturação destes espaços é necessário considerar que as comunidades se fazem de relações e que esse deve ser um foco importante na ação da liderança. Muitos dos artigos apresentaram o conceito de lideranças formais e informais como importantes para a qualidade das trocas e para o aumento de participação ativa nas redes. Estes ativistas do conhecimento (Nonaka, Von Krogh, \& Voelpel, 2006) são os responsáveis pela coordenação de atividades de compartilhamento e criação de conhecimento, oferecendo valor às organizações e aos membros das comunidades.

As atividades e práticas destacadas nos artigos precisam ser entendidas em suas diferentes categorias. Há atividades que trazem as pessoas para a comunidade, valendo-se de sua busca instrumental por conhecimento. Há práticas que permitem o acesso ao conhecimento compartilhado por membros da comunidade e há práticas que fazem a transição da relação instrumental com a comunidade para uma relação de pertencimento e troca. 
As comunidades precisam contar com uma diversidade de atividades e pontos de contato, de modo que a relação de dar e receber conhecimento seja viabilizada e que as pessoas percebam que ganham conhecimento suficiente para fazer jus à sua contribuição na comunidade (Pivetta, 2016). Isso é um grande desafio, já que Davis et al. (2010) apontam que 90\% dos usuários da Web são "passantes", $9 \%$ contribuem ocasionalmente e 1\% contribuem de modo significativo. Estabelecer práticas que possam melhorar a estatística de contribuição é essencial para a sustentabilidade das comunidades de prática multialocadas e para que a aprendizagem possa fluir de modo adequado. Neste contexto, a questão de identidade e busca de reputação inerentes ao ser humano precisam ser tratadas (Piedade et al., 2009). Práticas tais como a descrição do perfil de cada participante, das atividades que desempenha e da relevância que consegue entre seus pares podem auxiliar na construção do senso de pertencimento e no engajamento para promover o compartilhamento de conhecimentos.

$\mathrm{O}$ estabelecimento de conexões e sua permanência devem ser preocupações das Comunidades de Prática multialocadas, tendo em vista que não podem contar com o contato diário que nutre as relações. A oferta de atividades híbridas, encontros presenciais que possam ser levados depois para o mundo virtual ou mesmo a realização de atividades virtuais, que promovam o encontro dos membros da comunidade, também são práticas que podem fortalecer a cultura do compartilhamento. Como Wanberg et al (2017) indicam, a maioria das conexões começa por atividades em que os membros de uma comunidade trabalham juntos em projetos, em situações em que estão ligados a uma cadeia hierárquica na organização ou em oportunidades de encontro viabilizadas pela participação em eventos. Considerar a realização de atividades conjuntas que promovam o encontro entre as pessoas da rede pode ser um bom disparador de comportamentos de compartilhamento.

A tecnologia tem um papel fundamental no funcionamento das CoPs multialocadas. Ainda que haja comunidades que fazem uso tímido de tecnologia, a maioria das comunidades estudadas faz uso intensivo da tecnologia para fazer frente ao fato de estarem distribuídas geograficamente. Neste sentido, a facilidade de uso, confiabilidade, a interface amistosa bem como a correção, clareza, relevância e utilidade dos conteúdos são fatores relevantes para que seus membros façam o compartilhamento de conhecimento e usem as plataformas tecnológicas oferecidas pela comunidade para coconstruírem conhecimento.

Um outro elemento a ser considerado é a leveza dos sistemas e a quantidade de trabalho exigida de seus participantes. Simplicidade é um conceito chave para o sucesso das comunidades de prática multialocadas. É certo que isso não é suficiente, mas é necessário. As pessoas têm inúmeras atividades que competem com as comunidades. Então, considerar processos que sejam ágeis e que não lhes cause sobrecarga de trabalho excessiva é importante. As pessoas precisam ser mobilizadas para usar o sistema e suas funcionalidades e, ao fazerem isso, precisam perceber que há uma relação 
adequada entre o tempo e a energia que precisam dispender para compartilhar o conhecimento e os benefícios que recebem por fazê-lo.

Por fim, um modelo único de práticas que promova o compartilhamento de conhecimento não existe. Os artigos revisados demonstram que há uma série de práticas possíveis de serem aplicadas e que elas não dizem respeito exclusivamente às práticas de compartilhamento propriamente dito. Há que se considerar que é preciso criar um espaço para que o compartilhamento possa acontecer; é preciso lançar mão de estratégias que atendam a diferentes motivações e níveis de compartilhamento de conhecimento; faz-se necessário lançar mão de práticas que promovam as relações entre os membros da comunidade; é preciso oferecer recursos tecnológicos adequados; assim como é essencial que haja uma liderança para gerir, nutrir e dar sustentabilidade ao compartilhamento de conhecimento nas CoPs multialocadas. A adaptação de tais práticas às características e objetivos da comunidade é que a torna um local agregador para que as relações se estabeleçam e o compartilhamento de conhecimento possa acontecer em tempo e profundidade suficientes para que se torne relevante para seus membros e possa contribuir de maneira eficiente com sua aprendizagem e desenvolvimento pessoal e profissional.

\section{Conclusão}

O presente estudo levantou e discutiu práticas utilizadas para compartilhamento de conhecimento em comunidades de prática, de conhecimento e de aprendizagem interorganizacionais, interpessoais virtuais ou intraorganizacionais deslocadas geograficamente e que foram chamadas neste estudo de Comunidades de Prática multialocadas.

Identificou-se que as comunidades precisam de um lugar agregador. Esse lugar pode ser físico ou virtual, mas é essencial que exista como uma referência de local para onde seus membros vão para buscar e compartilhar conhecimento. Também, observou-se que há uma evolução no grau de participação em uma comunidade, começando pela participação para acessar conhecimento, passando para a oferta de conhecimento para outros membros e evoluindo para a troca e cocriação de conhecimentos. Neste sentido, as comunidades precisam promover conexões e oferecer processos para que estas conexões se estabeleçam, a fim de favorecer que esta evolução aconteça e alcance níveis mais complexos e ricos de compartilhamento de conhecimento. A tecnologia mostrou-se um elemento relevante para o compartilhamento de conhecimento nas CoPs multialocadas. Questões de qualidade dos sistemas e de conteúdo, assim como de facilidade de uso, são importantes quando se trata de compartilhamento de conhecimento em tais comunidades. As comunidades também precisam tratar de aspectos de governança. Nesta perspectiva, o modelo de liderança, os mecanismos de incentivo ao compartilhamento de conhecimento e, também, as práticas de gestão, que tratam da 
sustentabilidade da comunidade são significativos para a qualidade do compartilhamento de conhecimentos realizada nas CoPs multialocadas.

Não há um conjunto padrão de práticas para que uma CoP multialocada viabilize e promova o compartilhamento de conhecimento entre seus membros. O que se pode concluir como denominador comum entre os artigos é que a escolha de tais práticas precisa levar em consideração os objetivos da comunidade, as características de seus membros, a natureza do conteúdo a ser compartilhado, os canais de compartilhamento de conhecimento e também os recursos disponíveis.

Esta revisão apresentou práticas de compartilhamento de conhecimento em CoPs multialocadas. Entende-se que os dados levantados e as temáticas descritas podem colaborar com a qualificação de projetos de compartilhamento de conhecimento e também oferecer subsídios para a estruturação de novas redes ligadas ao compartilhamento e criação de conhecimento. Também, oferece um conjunto categorias de análise de práticas de compartilhamento de conhecimento em CoPs multialocadas.

No entanto, o estudo tem suas limitações. As práticas levantadas nos artigos podem não expressar todo o conjunto das práticas adotadas por comunidades desta natureza, tendo em vista que se decidiu pela revisão exclusiva de artigos científicos, avaliados por pares, deixando de avaliar livros, relatórios e outras fontes de informação. Ao lado disso, com o avanço das tecnologias de comunicação e com o aumento de familiaridade dos indivíduos com essas tecnologias, possivelmente, as práticas de compartilhamento de conhecimento venham a passar por mudanças, $o$ que não foi discutido neste artigo.

Deste modo, sugere-se que outros estudos possam ser realizados para ampliar o conjunto de práticas de compartilhamento reportadas. Também, estudos para avaliar a eficácia e o impacto de práticas específicas na aprendizagem e atuação profissional dos membros das CoPs é uma outra via de estudo possível, que pode trazer maior entendimento sobre as práticas de compartilhamento de conhecimento em comunidades de prática multialocadas.

\section{Referências}

Al-Rasheed, Amal, \& Berri, J. (2016). Effective reuse and sharing of best teaching practices. Computer Applications in Engineering Education, 25, 163-178. https://doi.org/10.1002/cae.21776

Antonacci, G., Fronzetti Colladon, A., Stefanini, A., \& Gloor, P. (2017). It is rotating leaders who build the swarm: social network determinants of growth for healthcare virtual communities of practice. Journal of Knowledge Management, 21(5), 1218-1239. https://doi.org/10.1108/JKM11-2016-0504

APO. (2009). APO facilitator's guide. Tokyo: APO.

Apostolou, D., Mentzas, G., Baraboutis, K., \& Papadopoulou, S. (2004). Facilitating Knowledge Exchange and Decision Making within Learning Networks. Journal of Universal Computer 
Science, 10(3), 205-226. Retrieved from http://www.jucs.org/jucs_10_3/facilitating_knowledge_exchange_and/Apostolou_D.pdf

Ardichvili, A. (2008). Learning and knowledge sharing in virtual communities of practice: motivatores, barriers and enablers. Advances in Developing Human Resources, 10(4), 541-554. https://doi.org/10.1177/1523422308319536

Argote, L., McEvily, B., \& Reagans, R. (2003). Managing Knowledge in Organizations: An Integrative Framework and Review of Emerging Themes. Management Science, 49(4), 571-582. https://doi.org/10.1287/mnsc.49.4.571.14424

Basile, C. G. (2009). Intellectual capital: the intangible assets of professsional development schools. Albany: State University of New York Press.

Bontis, N., \& Nikitopoulos, D. (2001). Thought leadership on intellectual capital. Journal of Intellectual Capital, 2(3), 183-191. https://doi.org/10.1108/14691930110400182

Botelho, L. L. R., Cunha, C. C. de A., \& Macedo, M. (2011). O método de revisão integrativa nos estudos organizacionais. Gestão e Sociedade, 5(11), 121-136. Retrieved from https://moodle.ufsc.br/pluginfile.php/2476323/mod_resource/content/1/BOTELHO CUNHA O metodo da revisao integrativa nos estudos organizacionais.pdf

Bourdon, I., Kimble, C., \& Tessier, N. (2015). Knowledge sharing in online communities: the power game. Journal of Business Strategy, 36(3), 11-17. Retrieved from www.emeraldinsight.com

Bourhis, A., \& Dubé, L. (2010). "Structuring spontaneity": Investigating the impact of management practices on the success of virtual communities of practice. Journal of Information Science, 36(2), 175-193. https://doi.org/10.1177/0165551509357861

Braun, V., \& Clarke, V. (2012). Thematic analysis. In H. Cooper (Ed.), APA Handbook of Research Methods in Psychology - Research Designs (Vol. 2). https://doi.org/10.1037/13620004

Cheng, E. C. K. (2015). Knowledge Management for School Development. In Knowledge Management for School Education. https://doi.org/10.1007/978-981-287-233-3

Cheung, C. M. K., Lee, M. K. O., \& Lee, Z. W. Y. (2013). Understanding the continuance intention of knowledge sharing in online communities of practice through the post-knowledge-sharing evaluation processes. Journal of the American Society for Information Science and Technology, 64(7), 1357-1374. https://doi.org/10.1002/asi.22854

Dalkir, K. (2005). Knowledge Management in Theory and Practice. Oxford: Elsevier Inc.

Davenport, E., \& Hall, H. (2005). Organizational knowledge and communities of practice. Annual Review of Information Science and Technology, 36(1), 170-227.

https://doi.org/10.1002/aris.1440360105

Davenport, T. H., \& Prusak, L. (1998). Working knowledge: how organizations manage what they know. https://doi.org/10.1145/348772.348775

Davis, H. C., Carr, L. A., Hey, J. M. N., Howard, Y., Millard, D., Morris, D., \& White, S. (2010). Bootstrapping a culture of sharing to facilitate open educational resources. IEEE Transactions on Learning Technologies, 3(2), 96-109. https://doi.org/10.1109/TLT.2009.34

Hamunen, K., Virkkula, O., Hujala, T., Hiedanpaa, J., \& Kurttila, M. (2015). Enhancing informal 
interaction and knowledge co-construction among forest owners. Silva Fennica, 49(1), 1-15. https://doi.org/10.14214/sf.1214

Hara, N., Shachaf, P., \& Stoerger, S. (2009). Online communities of practice typology revisited. Journal of Information Science, 35(6), 740-757. https://doi.org/10.1177/0165551509342361

Hartung, K., \& Oliveira, M. (2013). Communities of Practice: creating and sharing knowledge. REGE, 20(3), 407-422. https://doi.org/10.5700/rege507

Ho, L.-A., \& Kuo, T.-H. (2013). How system quality and incentive affect knowledge sharing. Industrial Management \& Data Systems, 113(7), 1048-1063. https://doi.org/10.1108/IMDS-012013-0015

Husted, K., \& Michailova, S. (2009). Dual Allegiance and Knowledge Sharing in Inter-firm R\&D Collaborations. Organizational Dynamics, 39(1), 37-47. https://doi.org/10.1016/j.orgdyn.2009.10.004

Ipe, M. (2004). Knowledge Sharing in Organizations: A Conceptual Framework. Human Resource Development Review, 2(4), 337-359. https://doi.org/10.1177/1534484303257985

Kezar, A., \& Gehrke, S. (2015). Communities of transformation and their work scaling STEM reform. Retrieved from http://www.uscrossier.org/pullias/wpcontent/uploads/2016/01/communities-of-trans.pdf

Lee-Kelley, L., \& Turner, N. (2017). PMO managers' self-determined participation in a purposeful virtual community-of-practice. International Journal of Project Management, 35(1), 64-77. https://doi.org/10.1016/j.ijproman.2016.09.014

Li, M., \& Gao, F. (2003). Why Nonaka highlights tacit knowledge: a critical review. Journal of Knowledge Management, 7(4), 6-14. https://doi.org/10.1108/13673270310492903

Malone, D. (2002). Knowledge management: a model for organizational learning. International Journal of Accounting Information Systems, 3(2), 111-123. https://doi.org/10.1016/S14670895(02)00039-8

NHS. (2005). ABC of Knowledge Management. In ABC of Knowledge Management. Retrieved from http://www.fao.org/fileadmin/user_upload/knowledge/docs/ABC_of_KM.pdf

Nonaka, I., \& Konno, N. (1998). The concept of " ba ": Building a foundation for knowledge creation. California Management Review, 40(3), 40-54. https://doi.org/10.2307/41165942

Nonaka, I., \& Takeuchi, H. (1995). The knowledge creating company: how japanese companies create the dynamics of innovation. New York: Oxford University Press.

Nonaka, I., Von Krogh, G., \& Voelpel, S. (2006). Organizational knowledge creation theory: Evolutionary paths and future advances. Organization Studies, 27(8), 1179-1208. https://doi.org/10.1177/0170840606066312

Okoli, C., \& Schabram, K. (2010). A guide to conducting a systematic literature review of information systems research. Sprouts:Working Papers on Information Systems, 10(26), 10-26. Retrieved from https://pdfs.semanticscholar.org/31dc/753345d5230e421ea817dd7dcdd352e87ea2.pdf

Pan, S. L., \& Leidner, D. E. (2003). Bridging communities of practice with information technology in pursuit of global knowledge sharing. Journal of Strategic Information Systems, 12, 71-88. 
Retrieved from www.elsevier.com/locate/jsis

Pan, Y., Xu, Y., Wang, X., Zhang, C., Ling, H., \& Lin, J. (2015). Integrating social networking support for dyadic knowledge exchange: A study in a virtual community of practice. Information and Management, 52(1), 61-70. https://doi.org/10.1016/j.im.2014.10.001

Piedade, V. C. H., Alcará, A. R., Chiara, I. G. di, Tomaél, M. I., \& Rodrigues, J. L. (2009). Fatores que influenciam o compartilhamento da informação e do conhecimento. Perspectivas Em Ciência Da Informação, 14(1), 170-191. https://doi.org/10.1590/s1413-99362009000100012

Pivetta, E. M. (2016). Criação de valores em comunidades de prática: um framework para um ambiente virtual de ensino e aprendizagem bilíngue. (Universidade Federal de Santa Catarina). Retrieved from http://btd.egc.ufsc.br/wp-content/uploads/2016/05/Elisa-Maria-Pivetta.pdf

Polanyi, M. (1966). The tacit dimension. New York: Anchor Day Books.

Rathi, D., Given, L. M., \& Forcier, E. (2014). Interorganisational partnerships and knowledge sharing: The perspective of non-profit organisations (NPOS). Journal of Knowledge Management, 18(5), 867-885. https://doi.org/10.1108/JKM-06-2014-0256

Sánchez-Cardona, I., Sánchez-Lugo, J., \& Vélez-Gonzalez, J. (2012). Exploring the potential of communities of practice for learning and collaboration in a higher education context. Procedia Social and Behavioral Sciences, 46, 1820-1825. https://doi.org/10.1016/j.sbspro.2012.05.385

Sims, Julian M. (2018). Communities of practice: Telemedicine and online medical communities. Technological Forecasting and Social Change, 126, 53-63. https://doi.org/10.1016/j.techfore.2016.08.030

Soares, C. B., Hoga, L., Hoga, K., Peduzzi, M., Sangaleti, C., Yonekura, T., ... Delage, A. (2014). Revisão integrativa: conceitos e métodos utilizados na enfermagem. Revista Da Escola de Enfermagem USP, 48(2), 335-345. https://doi.org/10.1590/S0080-623420140000200020

Soekijad, M., Huis in 't Veld, M. A. A., \& Enserink, B. (2004). Learning and knowledge processes in inter-organizational communities of practice. Knowledge and Process Management, 11(1), 3 12. https://doi.org/10.1002/kpm.191

Topousis, Daria E., Dennehy, C. J., \& Lebsock, K. L. (2012). Nasa's experiences enabling the capture and sharing of technical expertise through communities of practice. Acta Astronautica, 81, 499-511. https://doi.org/10.1016/j.actaastro.2012.08.008

Wanberg, J., Javernick-Will, A., Asce, M., \& Taylor, J. E. (2017). Mechanisms to Initiate Knowledge-Sharing Connections in Communities of Practice. Journal of Construction Engeeniring and Management, 143(11), 1-10. https://doi.org/10.1061/(ASCE)CO.19437862.0001399

Wang, S., \& Noe, R. A. (2010). Knowledge sharing: A review and directions for future research. Human Resource Management Review, 20(2), 115-131. https://doi.org/10.1016/j.hrmr.2009.10.001

Wenger, E., \& Snyder, W. M. (2000). Communities of practice: The organizational frontier. Harvard Business Review, 1, 139-145. https://doi.org/10.1177/0170840603024003909

Whittemore, R., \& Knafl, K. (2005). The integrative review: an updated methodology. Journal of Advanced Nursing, 52(5), 546-553. 